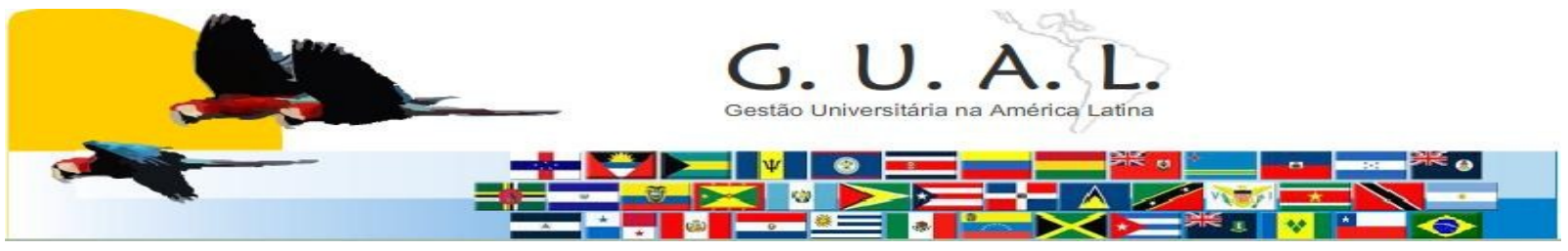

ISSN 1983-4535

\title{
A AVALIAÇÃO DE CURSO SUPERIOR: O CASO DO CURSO SUPERIOR DE TECNOLOGIA EM AGRONEGÓCIO DA UNIVERSIDADE FEDERAL DO PAMPA - UNIPAMPA
}

Sebastião Ailton da Rosa Cerqueira-Adão, Doutor Universidade Federal do Pampa - UNIPAMPA sebastiao.cerqueira@unipampa.edu.br

Tanice Andreatta, Doutora

Universidade Federal do Pampa - UNIPAMPA

taniceandreatta@unipampa.edu.br

Sérgio Ivan dos Santos, Doutor

Universidade Federal do Pampa - UNIPAMPA

sergiosantos@unipampa.edu.br

\author{
Fabiano Nunes Vaz, Doutor \\ Universidade Federal do Pampa - UNIPAMPA \\ fabianovaz@unipampa.edu.br \\ Cleiton Stigger Perleberg, Doutor \\ Universidade Federal do Pampa - UNIPAMPA \\ cleitonperleber@unipampa.edu.br \\ Ana Cristina do Amaral Lovato, Especialista \\ Universidade Federal do Pampa - UNIPAMPA \\ analovato@unipampa.edu.br
}

\section{RESUMO}

Este artigo teve como objetivo identificar a percepção dos discentes e docentes do Curso Superior de Tecnologia em Agronegócio da Universidade Federal do Pampa - UNIPAMPA no que tange às atividades de ensino, pesquisa, extensão, gestão e infraestrutura. $\mathrm{O}$ estudo foi desenvolvido sob a forma de pesquisa de opinião, com a utilização da abordagem quantitativa e utilização de instrumento de coleta de dados eletrônico contendo questões fechadas. De um modo geral os resultados apontaram que docentes e discentes avaliam a maioria dos indicadores elencados na pesquisa como sendo de bom a muito bom. Por fim conclui-se que esta primeira auto-avaliação do Curso de Agronegócio poderá orientar o coordenador de curso, bem como a alta gestão, em ações que assegurem a manutenção dos pontos positivos, assim como orientar ações acerca de aspectos que deverão ser melhorados ao longo dos próximos semestres.

Palavras-chave: Avaliação institucional. Auto-avaliação. Curso de Agronegócio. UNIPAMPA. 


\section{INTRODUÇÃO}

As organizações, de um modo geral, estão percebendo através de constantes avaliações a necessidade de agir de modo diferente para sobreviverem no mundo atual. Mesmo as organizações de sucesso todo o tempo buscam novos padrões de comportamento com o objetivo de melhoria, senão, de consolidação e garantia de sua posição no ramo de atuação ao qual pertencem.

Este padrão de qualidade está sendo requisitado também das instituições de ensino superior, em que para atender aos anseios da sociedade as universidades necessitam identificar elementos que as diferenciem de outras instituições.

Neste sentido, a avaliação institucional é vista como uma ferramenta adequada para o levantamento de pontos fortes e fracos, garantindo à universidade agilidade no processo de mudança e melhoria contínua de sua qualidade.

Os debates sobre avaliação e qualidade no ensino superior vem ganhando cada vez mais espaço na mídia nacional. A avaliação institucional tomou forma e corpo no ensino superior brasileiro, transformando-se em uma preocupação que envolve tanto a comunidade interna e externa à universidade. A importância do processo de avaliação insere-se no contexto da tomada de decisão das universidades no sentido em seus resultados direcionam às ações necessárias para a melhoria do funcionamento e do desempenho das atividades que estas instituições exercem e dos "produtos" (serviços e métodos) por elas gerados.

Convém ressaltar que qualidade e avaliação andam de mãos dadas vez que os estudos sobre qualidade remetem para a avaliação e o ato de avaliar pressupõe valores desejados em relação a um determinado objeto.

Por sua vez, a maioria dos instrumentos disponíveis para o processo de avaliação, tende a reduzir qualidade a dados meramente quantitativos, como se estes, de per si, fossem capazes de abarcar a dimensão qualitativa ali existente.

Diante disto, o estudo ora apresentado teve por objetivo identificar a percepção dos discentes e docentes em relação ao Curso Superior de Tecnologia em Agronegócio da Universidade Federal do Pampa - UNIPAMPA, no que tange às atividades de ensino, pesquisa, extensão, gestão e infraestrutura.

Este estudo caracterizou-se como relevante uma vez que permitiu captar a percepção de parte da comunidade acadêmica, ou seja, dos discentes e docentes do Curso Superior de 
Tecnologia do Agronegócio em relação ao funcionamento do respectivo curso. Ao mesmo tempo, estudos desta natureza, além de servir de referência para outros cursos e/ou universidades também dão visibilidade às atividades dos docentes, assim como apontam os pontos fortes e os pontos vulneráveis das atividades educacionais. A partir disso, o processo de tomada de decisão, assim como o processo de planejamento, quando necessários, são orientados por um instrumento formal.

\section{APORTE TEÓRICO}

A avaliação tem se constituído em tema relevante sendo identificada como um instrumento necessário à orientação de rumos que conduzam à eficiência e à qualidade dos serviços oferecidos pelas instituições de ensino superior no Brasil.

Ao fazer a retrospectiva histórica da avaliação institucional de caráter universitário Amorim (1982 apud CERQUEIRA, 2003), se destaca ao esclarecer que a avaliação tem se caracterizado como um modelo social em que seus segmentos humanos, permanentemente, buscam a descoberta e o domínio do saber.

O autor acima esclarece que o projeto avaliativo da universidade, em princípio, não pode ser diferente daquele conhecido como avaliação "dominadora". Amorim (1982 apud CERQUEIRA, 2003) identifica que as instituições universitárias se estruturaram em função da constante interferência das elites dominantes na busca de apropriação ideológica do conhecimento produzido por estas instituições, sendo que desde a implantação das primeiras escolas superiores do país, limitando e cerceando o caminho da democratização destas instituições. Esta apropriação, desde o início, aconteceu através de atos legais e de mecanismos de controle das ações acadêmicas e administrativas derivadas do trabalho desenvolvido.

Para Neiva (1989) a avaliação individual das instituições de ensino superior é um processo a ser conduzida por comissões externa à instituição, especialmente designada pela Secretaria de Educação Superior do Ministério da Educação.

A autora esclarece que esta comissão deve considerar, entre outros os seguintes aspectos: eficiência da atividade-meio em relação aos objetivos da instituição; adequação dos currículos dos cursos de graduação, inserção da instituição na comunidade local e regional; produção científica, cultural e tecnológica. 
Compreende-se então que a universidade como qualquer organização, deve ser avaliada em termos da eficiência econômica e da eficácia social de suas atividades conforme Belloni et al (apud CERQUEIRA, 1998).

Para este autor a avaliação sistemática é um instrumento que estimula o aprimoramento da qualidade das atividades e, ainda, contribui para que seja verificado o atendimento dos objetivos e finalidades da instituição.

Neste sentido, a universidade brasileira necessita ser avaliada como um todo. A diversidade em relação ao que seja qualidade e como ela se configura nas instituições de ensino superior, vem gerando interpretações que causam muita polêmica no seio acadêmico, o que requer cuidado na sua investigação (BUARQUE, 1994; LEITE E BORDAS, 1994; BELLONI, 1995; CUNHA, 1995;).

Conforme se interpreta em Dias Sobrinho (1995), qualidade nas instituições de ensino superior remete à questão "qualidade na educação", expressão esta que não apresenta sentido unívoco, nem pode ser apreendida de forma absoluta e incontestável.

Ristolff et al (1993) citam que para avaliação interna ou auto-avaliação institucional, a universidade se pauta em procedimentos como organizar, analisar, descrever, interpretar e avaliar os dados a partir das fontes de informações que já possui, por exemplo: planos departamentais, projetos, resoluções e outros que virem a instituir como seminários, fóruns, consulta à comunidade externa, avaliação dos docentes pelos discentes, questionários aplicados a egressos, entre outros, tendo sempre em vista os objetivos esperados a que se propõe à universidade.

$\mathrm{Na}$ visão dos autores acima, o rápido check-up da instituição é realizado pelos elementos indicadores extraído da análise do corpo docente, da investigação científica, da biblioteca, do corpo discente, dos egressos, dos investimentos, salários e/ou carga horária, números de publicações, prestação de serviços e computadores. Este modelo utilizado pelo MEC a partir da segunda metade da década de 90 visava tão somente analisar rendimentos, não aprofundando a questão da qualidade em toda a sua extensão. Observa-se, então, uma grande tendência de explicar o ensino superior unicamente pelos aspectos quantitativos.

$\mathrm{Na}$ realidade, as decisões sobre o sentido e a condução da avaliação institucional das universidades dizem respeito ao que e ao como avaliar frente à tensão instalada entre duas lógicas que orientam o processo valiativo: a lógica reguladora e a lógica emancipadora. 
Leite e Bordas (1994), afirmam que estas duas lógicas vêm presidindo a discussão e a ação avaliativa, desenvolvidas no complexo campo das estremecidas relações EstadoUniversidade-Sociedade.

As mesmas autoras esclarecem essas lógicas que orientam o processo avaliativo como sendo aquela seguida pelo Estado, que tem na avaliação de resultados ou de produtos, na combinação quantitativo/qualitativo e, na comparatividade sua via própria de sentido e desenvolvimento de critérios.

Belloni (1995) frisa que a avaliação do ensino superior tem sido regulamentada, em geral, via decretos e portarias, destinando-se a normatização das funções de supervisão e controle, próprias do poder executivo.

Para a autora, antes mesmo da aprovação da Lei de Diretrizes e Bases da Educação LDB, o Governo desencadeou a formulação e implementação de diretrizes sobre avaliação.

Na visão de Belloni (1995) a Lei 9131/95 que, de certo modo, dá as bases sistemáticas de avaliação ainda vigente, uma vez que não foi alterada pela LDB/96, determinou ao MEC realizar avaliações periódicas das instituições e dos cursos de nível superior. Para tal seria necessário o uso de procedimentos e critérios abrangentes dos diversos fatores que determinam a qualidade e a eficiência das atividades de ensino, pesquisa e extensão.

Para Belloni (1995) avaliação institucional em educação busca ser um instrumento para o aprimoramento da gestão acadêmica e administrativa, tanto das instituições quanto dos sistemas educacionais, com vistas à melhoria da qualidade e de sua relevância social.

Dias Sobrinho (apud Belloni, 1995) aborda que a avaliação é mais do que apenas um debate técnico ou metodológico, ou um conjunto de critérios para credenciamento ou rankeamento de instituições de ensino superior. Ela implica um "empreendimento ético e político".

Na prática a avaliação tem sido percebida com um conjunto de métodos e critérios para identificar pontos positivos e negativos relacionados à gestão das instituições universitárias. Paradoxalmente, tem-se que o valor que se busca com a avaliação não pode ser absolutizado a partir de indicadores parciais, por melhor que seja a metodologia utilizada, ou por concepções interpretativas que enrijeçam perspectivas, diz Ristoff (1999).

Firme (1999), outra pesquisadora da avaliação nas instituições de ensino superior aponta que não se pode perder de vista as dificuldades de formulação de indicadores para se 
avaliar as instituições universitárias, dadas as características que as tornam atípicas em relação às outras organizações. Na visão da autora acima, parece que no caso das universidades tanto a definição e quanto a construção de indicadores para avaliação exigem um trabalho conceitual e metodológico para validação dos mesmos.

Ainda com base em Firme (1999) as universidades, com suas situações atípicas, para se enquadrarem nesta abordagem da avaliação, necessitam assumir com coragem a autocrítica, a auto-avaliação, revendo suas dificuldades e seus problemas. Isto tudo pode acontecer sem que as universidades renunciem características peculiares que as diferenciem, racionalmente falando, de qualquer outra organização inventada pela humanidade.

Como base estratégica para a melhoria da qualidade, alicerçada na autocrítica do cumprimento de suas funções, a avaliação é hoje uma necessidade compartilhada por boa parte das instituições de ensino superior no país.

Ainda fazendo referência a formulação de critérios para avaliação, Sguissardi (1999) comenta que avaliar o ensino superior é preciso e urgente, mas é necessário saber, de que avaliação se está falando. O autor ressalta que, para a avaliação do ensino superior impõese de antemão o exercício da crítica às diferentes propostas de avaliação, nesta época de tantos apelos e urgências fundadas em princípios e conceitos tidos como universais.

Assim sendo, a avaliação do Curso Superior de Tecnologia em Agronegócio da UNIPAMPA constitui esforço para conhecer, diagnosticar e tratar eventuais situações de não conformidade com o que se espera de um curso superior tecnológico de qualidade.

O esforço do qual se fala aqui é o da busca da Comissão de Avaliação do Curso Superior de Tecnologia em Agronegócio - CAC de propor meios para o levantamento de um conjunto de dados e informações para que o Curso possa se conhecer e assim, quando necessário, redirecionar suas ações de ensino, pesquisa, extensão e gestão. Tudo isso alinhado com os preceitos de avaliação da Comissão Central de Avaliação da UNIPAMPA, e sob as orientações da Comissão Local de Avaliação do Campus Dom Pedrito/RS.

\section{MÉTODO}

Esta pesquisa foi desenvolvida sob a forma de pesquisa de opinião realizada no Curso Superior de Tecnologia em Agronegócio da UNIPAMPA. No âmbito organizacional, a pesquisa de opinião é considerada o melhor caminho para se conhecer a opinião dos públicos 
de interesse da organização a respeito de determinado tema. Segundo Kunsch (apud CHAMUSCA E CARVALHAL, 2005), “a pesquisa de opinião se constitui em um dos tipos de pesquisas mais relevantes para a área de relações públicas" e pode ser realizada para se analisar as "relações com os empregados, consumidores, acionistas, revendedores, comunidade, imprensa, poderes públicos", dentre outros.

Ressalta-se que a pesquisa apoiou-se no método quantitativo de análise, com utilização de média e desvio padrão.

Para desenvolver a avaliação a Comissão de Avaliação do Curso de Agronegócio $\mathrm{CAC}$ estabeleceu diretrizes mais gerais:

a) Coleta dos dados: a utilização de um questionário fechado como instrumento de coleta eminentemente eletrônico e despersonalizado; As questões foram respondidas considerando um escore de 1 a 5 , onde as equivalências foram assim constituídas: (1) muito ruim (2) ruim (3) regular (4) bom (5) muito bom.

b) Interpretação, análise e tratamento dos dados: Tabulação dos dados por meio de programação eletrônica.

c) População e amostra: a população questionada foi formada pelo conjunto de docentes e discentes das disciplinas ministradas no segundo semestre de 2010 no do curso. Responderam os respectivos instrumentos de avaliação 42\% dos discentes matriculados no curso matriculados no segundo semestre de 2010 e $80 \%$ dos docentes envolvidos no processo. A amostra foi idêntica a população.

Convém ressaltar que antes da aplicação dos instrumentos a Comissão de Avaliação (CAC) apresentou à Comissão de Curso uma proposta preliminar dos itens que estariam sendo avaliados, bem como solicitou sugestão e contribuição dos professores e representantes discentes. Com base nestas contribuições foi posteriormente elaborado o questionário final utilizado na avaliação.

O instrumento de coleta de dados foi organizado em cinco blocos. Sendo que os blocos um, dois e cinco contém questões idênticas para discentes e docentes e abordaram questões relacionadas à adequação das salas de aula, da biblioteca e dos laboratórios de ensino. O bloco dois tratou das percepções dos discentes e docentes acerca dos serviços administrativos e controles acadêmicos. O bloco cinco tratou das percepções de discentes e docentes em torno das atividades de pesquisa e extensão. 
No bloco três do instrumento aplicado junto aos discentes buscou-se avaliar as relações entre os docente/discentes.

Convém ressaltar que os discentes responderam questões relacionadas a cada disciplina/docente separadamente. No entanto, os dados específicos de cada disciplina/docente foram remetidos a um relatório específico para o coordenador do curso. $\mathrm{Na}$ publicização dos resultados foram divulgadas médias gerais das disciplinas.

O Bloco quatro tratou de questões relacionadas à auto-avaliação do respondente. Com relação aos discentes a intenção foi captar a percepção destes em relação ao seu desempenho nas diferentes disciplinas cursadas. No caso dos docentes buscou-se que esta categoria imprimisse as suas em relação às disciplinas ministradas no primeiro semestre de 2010.

\section{A AVALIAÇÃO DO CURSO SUPERIOR DE TECNOLOGIA EM AGRONEGÓCIO DA UNIPAMPA NA PRÁTICA}

A Universidade Federal do Pampa - UNIPAMPA é uma universidade multicampi que foi implantada a partir da política de expansão e renovação das instituições federais de educação superior. Hoje esta universidade federal está organizada em 10 campi que estão distribuídos na metade sul do Rio Grande do Sul conforme Figura 1 abaixo.

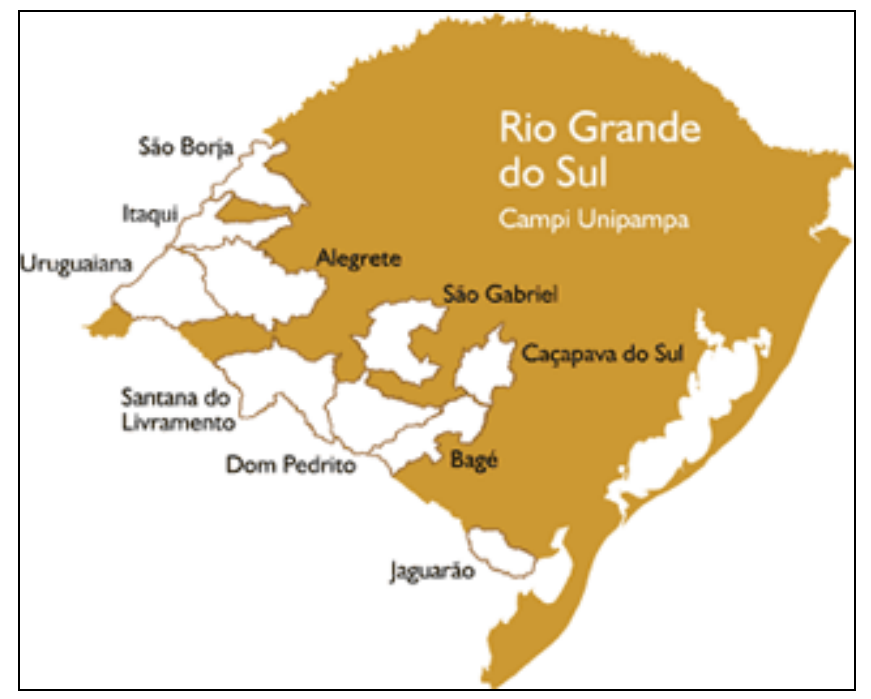

Figura 1 Localização de Campus da Universidade Federal do Pampa Fonte: UNIPAMPA, 2011

O Campus Dom Pedrito, situado entre as cidades de Bagé e Santana do Livramento é responsável pelo desenvolvimento de cursos voltados às ciências agrárias com os cursos de 
Zootecnia e Bacharelado em Enologia, bem como aloca o Curso Superior de Tecnologia em Agronegócio.

Vale ressaltar que o agronegócio está presente em todo território do Pampa Gaúcho, constituindo-se mola propulsora da economia dos municípios que fazem fronteira com o Uruguai e a Argentina. Trata-se de uma região do país com solos férteis e profundos, com extensas várzeas de topografia relativamente plana, que estimulam a produção de lavouras irrigadas, como as grandes áreas de plantação de arroz e a pecuária com vasta produção de bovinos e ovinos. No entanto, esta mesma região tem problemas de desenvolvimento sócioeconômico, característicos da "metade sul” do Rio Grande do Sul.

O reconhecimento das condições regionais e a necessidade de ampliar a oferta de ensino superior gratuito e de qualidade nesta região motivaram a proposição dos dirigentes dos municípios da área de abrangência da UNIPAMPA a pleitear, junto ao Ministério da Educação, uma instituição federal de ensino superior. $O$ atendimento a esse pleito foi anunciado no dia 27 de julho de 2005, em ato público realizado na cidade de Bagé.

Implantada em uma região que já foi destaque de produção primária, mas que atravessa problemas sérios de desenvolvimento socioeconômico, a UNIPAMPA reconhece que ações isoladas não são capazes de reverter o quadro atual. Cabe realizar a integração com os atores que já estão em movimento em prol da região. A estrutura multicampi facilita essa relação e promove o conhecimento das realidades locais, com vistas a subsidiar ações focadas na sua região.

O Curso Superior de Tecnologia em Agronegócio, apesar de estar sediado no Campus Dom Pedrito, tem a possibilidade de transitar por toda a região de abrangência da UNIPAMPA, realizando atividades complementares focadas na formação acadêmica em prol do desenvolvimento regional sustentável.

O desenvolvimento do curso baseia-se no Decreto 5.773/06, que dispõe sobre o exercício das funções de regulação, supervisão e avaliação de Instituições de Educação Superior, Cursos Superiores de Graduação e seqüenciais no Sistema Federal de Ensino e, ainda, considerando o Catálogo Nacional de Cursos Superiores de Tecnologias elaborados pelo MEC.

O Curso Superior de Tecnologia em Agronegócio é composto de disciplinas nas modalidades presenciais no decorrer de sete semestres. Poucas disciplinas apresentam pré- 
requisitos e têm direcionamento à aplicação prática imediata no exercício profissional do egresso. As ementas das disciplinas contam com temas que estão fundamentados em atividades do agronegócio existente na região.

As atividades extraclasses também são favorecidas pelas parcerias com empresas da região.

À medida que o curso foi se desenvolvendo e com o ingresso de novos docentes e técnicos assuntos educacionais passou-se a discutir a necessidade, assim como a funcionalidade de uma comissão de avaliação de curso; de um instrumento de avaliação; da institucionalização de uma avaliação semestral sistemática; assim como da implementação de ações visando manter os pontos positivos e de ações corretivas para encaminhar soluções para aqueles itens identificados como frágeis identificados a partir da auto-avaliação

Neste sentido, a comissão de avaliação foi instaurada no mês de novembro de 2010 com o intuito de institucionalizar uma avaliação permanente no Curso Superior de Tecnologia em Agronegócio. Em reuniões realizadas entre os meses de fevereiro e abril foi discutida sistematicamente a necessidade da avaliação bem como o teor desta avaliação, a população a ser considerada, a forma e o tipo de consulta a ser feita e os indicadores que seriam utilizados. Com base nas discussões realizadas nas referidas reuniões foram decididas as seguintes questões:

- Realização de pesquisa de opinião pela aplicação de formulário eletrônico;

- Terminais exclusivos para este fim localizados no hall de entrada da Universidade;

- Disponibilidade do instrumento para a comunidade acadêmica dos dias 10/05/2011 a 12/05/2011;

- Participantes: docentes e discentes que participaram do curso no segundo semestre de 2010;

- Forma de participação: voluntária.

- O controle de preenchimento foi por lista impressa, em que os discentes e docentes apontaram a sua participação.

- Período avaliado: segundo semestre de 2010.

- 16/05/2011 a 23/05/2011 sistematização dos dados e realização de relatório com os resultados principais;

- A partir de 23/05/2011 apresentação dos resultados de forma oral n Comissão de Curso e nas salas de aulas do Curso;

- A partir de 23/05/2011 divulgação dor resultados na forma escrita na página do curso e nos murais da universidade. 


\section{RESULTADOS E DISCUSSÃO}

A auto-avaliação configurada pelos discentes e docentes do Curso superior de Tecnologia em Agronegócio vai ao encontro das proposições das autoras acima referidas. É com esse intuito que a Comissão de Avaliação do Curso Superior de Tecnologia no Agronegócio busca institucionalizar a auto-avaliação semestral. Somente a partir disso é possível realizar o planejamento, a execução e monitoramento das atividades de um curso superior no médio e longo prazo.

Para Belloni (1995) avaliação institucional em educação busca ser um instrumento para o aprimoramento da gestão acadêmica e administrativa, tanto das instituições quanto dos sistemas educacionais, com vistas à melhoria da qualidade e de sua relevância social.

Outra forma de definir a avaliação é identificá-la como um instrumento que vai além de um relatório diagnóstico, como um processo que sirva de orientação às atividades institucionais e, inclusive, de seus objetivos. Portanto, conceber a avaliação como um instrumento de ação política que dependa do compromisso institucional é a explicitação de Freitas (1995).

A autora define avaliação institucional como uma maneira de estimular o aprimoramento de uma atividade, evitando que a rotina descaracterize os objetivos e finalidades desta mesma atividade. Neste sentido, o processo de avaliação desencadeado pela UNIPAMPA busca identificar a relação dos objetivos organizacionais expressos no Plano de Desenvolvimento Institucional, no Projeto Institucional, bem como no Projeto Político Pedagógico dos Cursos.

Belloni (1995) defende a tese de que é possível desenvolver um sistema de avaliação que vise o aperfeiçoamento da qualidade da educação - isto é, do ensino, da aprendizagem, da pesquisa e da gestão institucional - com a finalidade de transformar a escola atual em uma instituição voltada para e comprometida com a democratização do conhecimento e da educação, assim como com a transformação da sociedade. Este é o papel ou função social da avaliação e é necessário aprender como implementá-la.

Convém ressaltar que o resultado predominante da auto-avaliação girou em torno dos escores quatro (4) e cinco (5). Isso denota que, de um modo geral, na visão dos discentes e discentes, os aspectos avaliados variam entre "bom" e "muito bom". 
Em relação à adequação das salas de aula, a média abaixo de quatro em relação à ventilação relaciona-se à inexistência de condicionadores de ar. Considerando que no Rio Grande do Sul a estação outono-inverno é recorrente as temperaturas muito baixas, assim como no verão as temperaturas são elevadas, isso acaba por criar um desconforto durante as aulas (TAB. 1).

Tabela 1 - Percepções dos discentes e docentes a respeito da adequação das salas de aula

\begin{tabular}{lcccc}
\multicolumn{1}{c}{ Percepções } & \multicolumn{2}{c}{ DISCENTES } & \multicolumn{2}{c}{ DOCENTES } \\
\hline Acessibilidade & Média & $\begin{array}{c}\text { Desvio } \\
\text { Padrão }\end{array}$ & Média & $\begin{array}{c}\text { Desvio } \\
\text { Padrão }\end{array}$ \\
Iluminação & 4,58 & 0,76 & 4,00 & 1,73 \\
Acústica & 4,11 & 0,86 & 4,00 & 1,70 \\
Ventilação & 4,34 & 0,63 & 4,20 & 1,30 \\
$\begin{array}{l}\text { Limpeza, conservação } \\
\text { Equipamentos (quadros, retroprojetor, }\end{array}$ & 3,16 & 1,26 & 4,00 & 0,70 \\
computador) & 4,51 & 0,56 & 4,80 & 0,40 \\
\hline
\end{tabular}

Fonte: Dados da Pesquisa de Campo

No que tange à adequação da biblioteca, enquanto os discentes entendem que os três itens avaliados estão bons, os docentes tem uma visão mais crítica. $\mathrm{O}$ escore mais baixo para a acessibilidade ao acervo tende a estar ligada ao fato de que a Biblioteca está instalada no segundo andar. Devido ao mau funcionamento do elevador, cadeirantes e indivíduos portadores necessidades especiais tem o acesso dificultado e/ou comprometido quando demandam os serviços deste setor (TAB. 2).

Por outro lado, no que se refere ao acesso a livros e periódicos a dificuldade reside, principalmente na diversidade de livros e na dificuldade de acesso a periódicos. De um modo geral as solicitações de livros e periódicos são anuais, no entanto, tem sido uma dificuldade aumentar a diversidade de títulos em todas as áreas do curso. 
Tabela 2 - Percepções dos discentes e docentes a respeito da adequação da Biblioteca

\begin{tabular}{lcccc}
\multicolumn{1}{c}{ Itens } & \multicolumn{2}{c}{ DISCENTES } & \multicolumn{2}{c}{ DOCENTES } \\
\multicolumn{1}{c}{ Média } & $\begin{array}{c}\text { Desvio } \\
\text { Padrão }\end{array}$ & Média & $\begin{array}{c}\text { Desvio } \\
\text { Padrão }\end{array}$ \\
$\begin{array}{l}\text { O acervo de livros e periódicos atende às } \\
\text { necessidades do curso (quantidade e } \\
\text { diversidade) }\end{array}$ & 4,04 & 0,88 & 3,40 & 0,90 \\
$\begin{array}{l}\text { Acessibilidade ao acervo } \\
\text { Área física da biblioteca }\end{array}$ & 4,22 & 0,93 & 3,60 & 1,70 \\
\hline
\end{tabular}

Fonte: Dados da Pesquisa

Já em relação à adequação da estrutura dos laboratórios de ensino, tanto na visão dos discentes como dos docentes o rankeamento das médias varia entre bom e muito bom. Neste sentido, o laboratório de informática possui máquinas suficientes e funciona normalmente. Além disso, a rede wireless permite o acesso à internet por intermédio de notebooks, netbooks e dispositivos móveis e no prédio e seu entorno. Convém ressaltar que em função do funcionamento do curso de Zootecnia e Bacharelado em Enologia, as disciplinas profissionalizantes do Curso Superior de Tecnologia em Agronegócio, na área de produção animal e de produção vegetal, dispõem para utilização os modernos laboratórios nesta área (TAB. 3)

Tabela 3 - Percepções dos discentes e docentes a respeito da adequação dos Laboratórios de Ensino

\begin{tabular}{lcccc}
\hline \multicolumn{1}{c}{ Itens } & \multicolumn{2}{c}{ DISCENTES } & \multicolumn{2}{c}{ DOCENTES } \\
& Média & $\begin{array}{c}\text { Desvio } \\
\text { Padrão }\end{array}$ & Média & $\begin{array}{c}\text { Desvio } \\
\text { Padrão }\end{array}$ \\
Acessibilidade & 4,13 & 0,77 & 4,25 & 1,0 \\
Área física & 4,28 & 0,77 & 4,75 & 0,5 \\
Disponibilidades de equipamentos & 4,19 & 0,78 & 4,75 & 0,5 \\
Acesso ao sinal de internet (wireless) & 4,15 & 0,78 & 4,50 & 1,0 \\
\hline
\end{tabular}

Fonte: Dados da Pesquisa

De um modo geral a avaliação de ambos os grupos de respondentes também é positiva no que se refere ao funcionamento dos serviços administrativos e controles acadêmicos. No 
conjunto de itens os discentes valorizam como bom funcionamento da parte administrativa, sobretudo no que se refere ao atendimento da secretaria acadêmica e os horários de atendimento. Os docentes, além destes dois aspectos, também destacam a rapidez nos encaminhamentos em relação a documentos e questionamentos.

Para Goergen (2000) a avaliação não se restringe apenas à mensuração da performance relativa as funções tradicionais de pesquisar, ensinar e prestar serviços, mas envolve também a existência e a identidade da universidade. Neste sentido foi é possível identificar uma análise favorável em relação à satisfação de discentes e docentes em relação ao curso. Esse aspecto é muito importante, pois o envolvimento efetivo da comunidade acadêmica tende em resultar de ações que visem construir uma identidade do curso e/ou da universidade. Também é observada uma avaliação positiva dos docentes e discentes em relação à atuação da coordenação do curso (TAB. 4).

Tabela 4 Percepções dos discentes e docentes a respeito da adequação do funcionamento dos serviços administrativos e controles académicos

\begin{tabular}{lcccc}
\multicolumn{1}{c}{ Itens } & \multicolumn{1}{c}{ DISCENTES } & \multicolumn{2}{c}{ DOCENTES } \\
\multicolumn{1}{c}{ Média } & $\begin{array}{c}\text { Desvio } \\
\text { Padrão }\end{array}$ & Média & $\begin{array}{l}\text { Desvio } \\
\text { Padrão }\end{array}$ \\
$\begin{array}{l}\text { O atendimento da secretaria } \\
\text { acadêmica }\end{array}$ & 4,30 & 0,81 & 4,40 & 0,90 \\
$\begin{array}{l}\text { O acesso a documentos e } \\
\text { informações }\end{array}$ & 4,36 & 0,70 & 4,20 & 0,80 \\
$\begin{array}{l}\text { A organização e o horário de } \\
\text { atendimento }\end{array}$ & 4,39 & 0,76 & 4,80 & 0,40 \\
$\begin{array}{l}\text { A adequação dos equipamentos } \\
\text { (computadores, quadro de aviso) }\end{array}$ & 4,26 & 0,71 & 4,00 & 1,00 \\
$\begin{array}{l}\text { O tempo de entrega e/ou de } \\
\text { resposta aos questionamentos e } \\
\text { documentos }\end{array}$ & 4,21 & 0,71 & $4,60^{\circ}$ & 0,50 \\
$\begin{array}{l}\text { O trabalho da coordenação do } \\
\text { curso }\end{array}$ & 4,09 & 1,00 & 4,20 & 0,80 \\
\hline \begin{tabular}{l} 
O grau de satisfação com o curso \\
\hline
\end{tabular} & 4,35 & 0,73 & 4,60 & 0,50 \\
\hline
\end{tabular}


A tabela 5 demonstra a percepção dos discentes e docentes no que tange às atividades de pesquisa e extensão. Neste aspecto chama atenção à contradição entre o envolvimento efetivo e o interesse em participar nas referidas atividades. Duas situações podem contribuir para essa configuração. A primeira, em relação aos discentes, tende a estar relacionado ao fato de que o curso funciona no turno da noite, e uma quantidade expressiva de acadêmicos (as) são trabalhadores em tempo integral e/ou parcial.

Nestes casos a disponibilidade de horário é um empecilho para a atuação efetiva destes discentes nos grupos de pesquisa e extensão. Em relação aos docentes, cabe lembrar que um número significativo destes ingressou recentemente na Universidade e/ou no curso. Desta forma, apesar do interesse, ainda não identificaram uma área afim ou ainda não estruturaram seus respectivos grupos de pesquisa e extensão.

Tabela 5 - Percepções dos discentes e docentes a respeito das atividades de pesquisa e extensão

\begin{tabular}{lcccc}
\hline \multicolumn{1}{c}{ Percepções } & \multicolumn{1}{c}{ DISCENTES } & \multicolumn{2}{c}{ DOCENTES } \\
\hline & Média & $\begin{array}{c}\text { Desvio } \\
\text { Padrão }\end{array}$ & Média & $\begin{array}{c}\text { Desvio } \\
\text { Padrão }\end{array}$ \\
\hline Envolvimento nos projetos de extensão & 3,79 & 0,98 & 3,50 & 1,30 \\
\hline $\begin{array}{l}\text { Envolvimento nos projetos de Pesquisa } \\
\text { Interesse em participar de projetos de }\end{array}$ & 3,78 & 1,05 & 3,25 & 1,30 \\
$\begin{array}{l}\text { extensão da UNIPAMPA } \\
\text { Interesse participar de projetos de }\end{array}$ & 4,20 & 0,72 & 4,00 & 1,40 \\
\hline \begin{tabular}{l} 
Pesquisa da UNIPAMPA \\
\hline
\end{tabular} & 4,22 & 0,76 & 4,50 & 0,60 \\
\hline
\end{tabular}

Fonte: Dados da Pesquisa

Conforme o exposto anteriormente, as tabelas 6, 7, e 8 são questões específicas de cada grupo de respondentes (discentes e docentes). Na tabela 6 é demonstrada a avaliação da relação discente-docente, na visão dos discentes. Deste modo, nos três aspectos avaliados o resultado girou entre o escore bom (4) e muito bom (5).

Cabe apontar que o corpo docente não só do curso, mas do próprio campus majoritariamente é configurado por doutores, e de áreas diversas do conhecimento. O regime de trabalho dos docentes é de dedicação exclusiva, o que possivelmente contribui para a boa relação com os discentes, assim como o desempenho satisfatório na prática educacional. 
Tabela 6 Percepções dos discentes sobre a relação discente-docente

\begin{tabular}{lcc}
\multicolumn{1}{c}{ Percepções } & Média & $\begin{array}{c}\text { Desvio } \\
\text { Padrão }\end{array}$ \\
$\begin{array}{l}\text { Discussões realizadas pelo professor de diferentes } \\
\text { correntes de pensamento demonstrando domínio do } \\
\text { conteúdo }\end{array}$ & 4,38 & 0,33 \\
$\begin{array}{l}\text { O professor utiliza diferentes formas de avaliação da } \\
\text { aprendizagem, relacionando teoria e prática profissional } \\
\text { (provas, seminários, pesquisas }\end{array}$ & 4,35 & 0,35 \\
$\begin{array}{l}\text { O professor é acessível dentro e fora da sala de aula } \\
\text { O nível das aulas ministradas }\end{array}$ & 4,44 & 0,25 \\
\hline
\end{tabular}

Fonte: Dados da Pesquisa

Obs: Neste item especificamente foi calculado a média dos escores de todas as disciplinas ministradas no primeiro semestre de 2011

Questionados sobre o seu próprio desempenho nas disciplinas, majoritariamente os discentes apontam que foi de bom a muito bom. De acordo com os escores, apontam como desempenho regular nas disciplinas de Matemática Financeira, assim como de Estatística Aplicada.

Tabela 7 - Percepções dos discentes sobre o seu desempenho nas respectivas disciplinas cursadas no primeiro semestre de 2011

\begin{tabular}{lcc}
\multicolumn{1}{c}{ Percepçõ es } & Média & Desvio Padrão \\
Disciplina de Alimentos e Alimentação Animal & 4,06 & 0,76 \\
Disciplina de Economia Rural & 4,34 & 0,76 \\
Disciplina de Estatística Aplicada & 3,64 & 1,14 \\
Disciplina de Produção Animal I & 4,23 & 0,77 \\
Disciplina de Matemática Financeira & 3,58 & 1,30 \\
Disciplina de Produção Vegetal I & 4,65 & 0,60 \\
Disciplina de Cadeias Produtivas Pecuárias & 4,47 & 0,74 \\
Disciplina de Cadeias Produtivas Agrícolas & 4,00 & 1,29 \\
Disciplina de Política Agrícola e Comércio Internacional & 4,45 & 0,69 \\
Disciplina de Administração em Agronegócios & 4,31 & 0,79 \\
Disciplina de Projeto Aplicado I & 4,18 & 0,87 \\
\hline
\end{tabular}


Na visão de Amado (apud CERQUEIRA, 1998) aborda a auto-avaliação como um momento importante dentro do processo avaliativo. Para o autor a auto-avaliação, como dispositivo analisador, pode facilitar a discussão de aspectos técnico-profissionais e aspectos ético-políticos que envolvam a construção de uma certa responsabilidade social.

Por fim, foi questionado aos docentes que avaliassem o seu desempenho nas disciplinas ministradas no primeiro semestre de 2010. Neste item foi observada a maior amplitude de escores. Esta amplitude tende a estar relacionada com a aptidão e/ou identidade de cada docentes com uma disciplina em específico. Também tende a refletir a percepção de melhoria progressiva na atividade.

Tabela 8 - Percepções dos docentes em relação à condução de sua própria disciplina

\begin{tabular}{lc}
\multicolumn{1}{c}{ Itens } & Média \\
Disciplina de Estatística Aplicada & 3,00 \\
Disciplina de Produção Animal I & 2,00 \\
Disciplina de Matemática Financeira & 3,00 \\
Disciplina de Produção Vegetal I & 5,00 \\
Disciplina de Economia Rural & 4,00 \\
Disciplina de Cadeias Produtivas Pecuárias & 5,00 \\
Disciplina de Cadeias Produtivas Agrícolas & 3,00 \\
Disciplina de Administração em Agronegócios & 5,00 \\
Disciplina de Política Agrícola e Comércio Internacional & 3,00 \\
Disciplina de Projeto Aplicado I & 5,00 \\
\hline \multicolumn{1}{c}{ Fonte: Dados da Pesquisa }
\end{tabular}

Ressalta Dias Sobrinho (2000) que a avaliação não é uma simples prestação de contas, controle da eficiência institucional, nem tampouco mera medida de rendimento de estudantes. Para este autor a avaliação não é instrumento de dominação e controle, mas mecanismo de conhecimento, compreensão e melhora da instituição e de seus agentes.

Para Dias Sobrinho (2004), de forma prática a avaliação é uma prática eminentemente técnica, cuja função é prestar informações objetivas, científicas, claras, incontestáveis, úteis para orientar o mercado e os governos. A sociedade tem o direito de saber quais são as boas instituições de ensino superior, os bons professores, quem oferece os melhores serviços, tudo isto baseado em parâmetros prévia e objetivamente estabelecidos. 


\section{CONSIDERAÇÕES FINAIS}

A Comissão de Avaliação do Curso - CAC do Curso Superior de Tecnologia em Agronegócio foi constituída com o propósito de iniciar e institucionalizar o processo de autoavaliação no referido curso.

A auto-avaliação do curso foi realizada em maio de 2011 teve por objetivo balizar ações que promovam melhorias e indiquem os pontos que devem ser observados para manter o curso com um padrão de qualidade adequado.

Em síntese, a auto-avaliação é vista pelos componentes da comissão como um instrumento que contribui para melhorias continua da qualidade nas atividades docentes, discentes, e das atividades meio. A ação inicial da CAC foi definir uma forma de coletar dados junto à comunidade do curso que contribuam para entender a percepção das pessoas a respeito ensino, pesquisa, extensão e gestão.

A CAC definiu como item relevante prospectar a opinião interna dos discentes e docentes em relação ao curso. Esta prospecção de opinião foi feita por meio de formulário eletrônico, disponibilizada em local único, em terminal exclusivo para este fim.

No formulário estão questionamentos relativos ao espaço físico, sistema de biblioteca e laboratório de ensino, serviços administrativos prestados pelo setor acadêmico, o desejo de participar e propor atividades de extensão e pesquisa. A relação discente-docente e docentediscente em relação ao desempenho acadêmico. Bem com, a formulação dos questionamentos foi realizada com a colaboração de membros externos à Comissão de Avaliação.

Em linhas gerais os resultados apontam que docentes e discentes avaliam a maioria dos indicadores como bom a muito bom. No entanto, existem aspectos que podem e devem ser melhorados ao longo dos próximos semestres.

Neste sentido, a Auto-avaliação do Curso de Agronegócio da UNIPAMPA passa a ser vista como uma ferramenta adequada para o levantamento de pontos fortes e fracos, garantindo ao curso agilidade no processo de mudança e melhoria contínua. Acrescenta-se ainda, que este processo de avaliação no Curso de Agronegócio propiciou uma reflexão maior sobre o uso e universalização de métodos e indicadores nos processos de avaliação das IES. 


\section{REFERÊNCIAS BIBLIOGRÁFICAS}

BELLONI, Isaura. Avaliação institucional na Universidade de Brasília. In: BALZAN, Newton, BUARQUE, C. A Aventura da universidade. São Paulo : Editora UNESP/Rio de Janeiro: Paz e Terra, 1994.

CERQUEIRA, S. A. R.; COLOSSI, N. Estudo da função extensionista e assistencial do hospital universitário da Universidade Federal de Santa Catarina. In: Amélia Silveira, Nelson Colossi, Cláudia Gonçalves de Souza.. (Org.). Administração universitária: estudos brasileiros. 1 ed. Florianópolis: Insular, 1998, v. 1, p. 177-212.

, S. A. R. O olhar de um administrador para a coerência e organicidade dos cursos de residência médica: um estudo de caso. Campinas: UNICAMP, 2003. Tese de doutorado apresentada ao Programa de Pós-graduação em Educação da Faculdade de Educação da Universidade Estadual de Campinas.

CHAMUSCA, Marcello; CARVALHAL, Márcia. Pesquisas de opinião: a opinião pública na construção de uma imagem pública favorável. In: RP em Revista. Salvador: FTC, 2005.

CUNHA, L. A. Avaliar qual universidade? In: Anais do I Seminário Brasileiro sobre Avaliação Institucional de Universidades. Campinas, SP: Unicamp, 1995

DIAS SOBRINHO, José (Org.). Avaliação Institucional: teoria e experiência. São Paulo: Cortez, 1995.

, José. Avaliação quantitativa, avaliação qualitativa: interações e ênfases.

In: Avaliação universitária em questão: reformas do Estado e da educação superior. Campinas: Autores Associados, 1997.

, José. Avaliação da Educação Superior. Petrópolis, RJ: Vozes, 2000.

FIRME, Thereza Penna. Avaliação tendências e tendenciosidades. In: Ensaios: Avaliação e políticas em educação. Rio de Janeiro: CESGRANRIO, 1999.

FREITAS, Iêda M. A. C. Avaliação da educação superior: fatores técnicos e políticos em universidades públicas brasileiras. Florianópolis, 226p. Dissertação (Mestrado em Administração), UFSC, 1995.

GOERGEN, Pedro. Avaliação universitária na perspectiva da pós-modernidade. Campinas/SP: Papirus, 2000.

LEITE, Denise e BORDAS, Merion Campos. Avaliação da Universidade Federal do Rio Grande do Sul: qualidade da diferença e a diferença da qualidade. In: Educación Superior e Sociedade, v. 5, n 1. Buenos Aires, 1994. 
NEIVA, Claúdio C. a avaliação como instrumento de apoio ao planejamento e tomada de decisões: a perspectiva da eficiência institucional e da qualidade do ensino dentro de um enfoque político. In: VAHL, Teodoro R. et ali (org.). Desafios da Administração Universitária. Florianópolis: UFSC, 1989.

RISTOFF, Dilvo Ilvo et al. Avaliação na Universidade Federal de Santa Catarina: uma proposta de metodologia. Florianópolis: UFSC, 1993.

RISTOFF, Dilvo Ilvo. Universidade em foco: reflexões sobre a educação superior. Florianópolis: Insular, 1999.

SGUISSARDI, Valdemar. Para avaliar propostas de avaliação do ensino superior. In: Avaliação Universitária em questão: reformas do Estado e da educação superior. Campinas/SP: Autores Associados, 1999. 


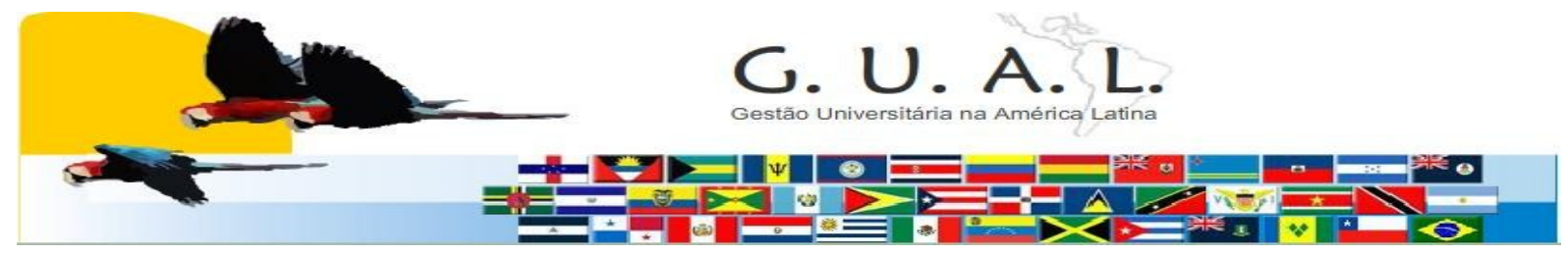

ISSN 1983-4535

\title{
EVALUATION OF SUPERIOR COURSE: THE CASE OF THE SUPERIOR COURSE OF TECHNOLOGY IN AGRIBUSINESS OF THE UNIVERSIDADE FEDERAL DO PAMPA - UNIPAMPA
}

Sebastião Ailton da Rosa Cerqueira-Adão, Doutor Universidade Federal do Pampa - UNIPAMPA sebastiao.cerqueira@unipampa.edu.br

Tanice Andreatta, Doutora

Universidade Federal do Pampa - UNIPAMPA

taniceandreatta@unipampa.edu.br

Sérgio Ivan dos Santos, Doutor

Universidade Federal do Pampa - UNIPAMPA

sergiosantos@unipampa.edu.br

\author{
Fabiano Nunes Vaz, Doutor \\ Universidade Federal do Pampa - UNIPAMPA \\ fabianovaz@unipampa.edu.br \\ Cleiton Stigger Perleberg, Doutor \\ Universidade Federal do Pampa-UNIPAMPA \\ cleitonperleber@unipampa.edu.br \\ Ana Cristina do Amara Lovatol, Especialista \\ Universidade Federal do Pampa - UNIPAMPA \\ analovato@unipampa.edu.br
}

\begin{abstract}
This article aims to identify the perceptions of students and professors of Superior Course of Technology in Agribusiness of the Universidade Federal do Pampa - UNIPAMPA when it comes to teaching, research, extension, management and infrastructure. The study was conducted in the form of opinion survey, using a quantitative approach and the use of an instrument for collecting electronic data with closed questions. In general the results showed that professors and students value most of the indicators listed in the survey as being good to very good. Finally we conclude that the first self-evaluation Course of Agribusiness can guide the higher management and coordinator on actions to ensure the maintenance of positive points as well as guide actions about aspects that should be improved over the next semester.
\end{abstract}

Keywords: Institutional evaluation. Self-evaluation. Agribusiness Course. UNIPAMPA. 